\title{
Sodium Channel-Dependent and -Independent Mechanisms Underlying Axonal Afterdepolarization at Mouse Hippocampal Mossy Fibers
}

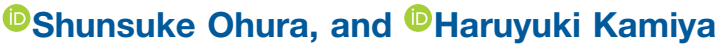

DOI:http://dx.doi.org/10.1523/ENEURO.0254-18.2018

Department of Neurobiology, Hokkaido University Graduate School of Medicine, Sapporo 060-8638, Japan

\section{Visual Abstract}
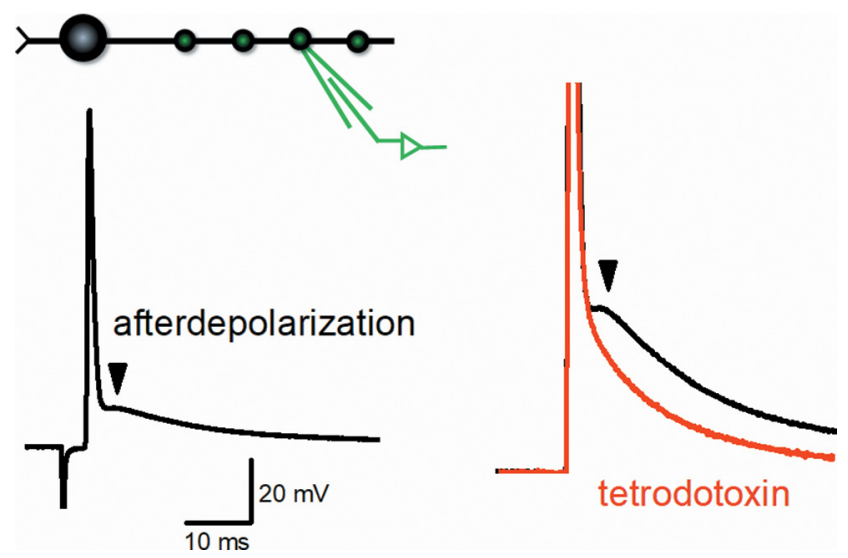

Action potentials propagating along axons are often followed by prolonged afterdepolarization (ADP) lasting for several tens of milliseconds. Axonal ADP is thought to be an important factor in modulating the fidelity of spike propagation during repetitive firings. However, the mechanism as well as the functional significance of axonal ADP remain unclear, partly due to inaccessibility to small structures of axon for direct electrophysiological recordings. Here, we examined the ionic and electrical mechanisms underlying axonal ADP using whole-bouton recording from mossy fiber terminals in mice hippocampal slices. ADP following axonal action potentials was strongly enhanced by focal application of veratridine, an inhibitor of $\mathrm{Na}^{+}$channel inactivation. In contrast, tetrodotoxin (TTX) partly suppressed ADP, suggesting that a $\mathrm{Na}^{+}$channel-dependent component is involved in axonal ADP. The remaining TTX-resistant $\mathrm{Na}^{+}$channel-independent component represents slow capacitive discharge reflecting the shape and electrical properties of the axonal membrane. We

\section{Significance Statement}

Axonal action potentials are often followed by depolarizing or hyperpolarizing afterpotentials. This study illuminated the mechanisms of ADP in the hippocampal mossy fibers, where morphologic as well as biophysical data were accumulated. We found that slow activating $\mathrm{Na}^{+}$channels are partly involved in ADP. Capacitive components also substantially contribute to ADP, suggesting that axonal shape and electrical properties are optimized for high-fidelity propagation during repetitive stimuli. We also tested the roles of $\mathrm{ADP}$ in the activity-dependent tuning of the presynaptic $\mathrm{Ca}^{2+}$ current. Action potential-driven $\mathrm{Ca}^{2+}$ entry into the axon terminals was facilitated by paired stimuli, possibly due to $\mathrm{Ca}^{2+}$ current facilitation by ADP. Therefore, ADP contributes to fine-tuning of transmitter release and ensures high-fidelity spiking of axons. 
also addressed the functional impact of axonal ADP on presynaptic function. In paired-pulse stimuli, we found that axonal ADP minimally affected the peak height of subsequent action potentials, although the rising phase of action potentials was slightly slowed, possibly due to steady-state inactivation of $\mathrm{Na}^{+}$channels by prolonged depolarization. Voltage clamp analysis of $\mathrm{Ca}^{2+}$ current elicited by action potential waveform commands revealed that axonal ADP assists short-term facilitation of $\mathrm{Ca}^{2+}$ entry into the presynaptic terminals. Taken together, these data show that axonal ADP maintains reliable firing during repetitive stimuli and plays important roles in the fine-tuning of short-term plasticity of transmitter release by modulating $\mathrm{Ca}^{2+}$ entry into presynaptic terminals.

\section{Key words: Action potential; afterdepolarization; axon; CA3; hippocampus; mossy fiber}

\section{Introduction}

The propagation of action potentials along axons is a fundamental process in the nervous system to reliably carry neuronal information to the target cells (Debanne et al., 2011; Kole and Stuart, 2012). Mechanisms enabling ultrafast and reliable spike signaling were studied extensively in various preparations of the central nervous system, including myelinated and unmyelinated axons. However, the mechanisms and functional consequences of axonal ADP, which often follows axonal action potentials and lasts for several tens of milliseconds, remain to be elucidated. Thus far, few studies have directly addressed the mechanisms for the generation of axonal ADP in the central nervous system, except for the calyx of Held axon terminals (Borst et al., 1995; Kim et al., 2010), which enable direct electrophysiological recording from the large axon terminals.

As local application of the $\mathrm{Na}^{+}$channel blocker tetrodotoxin (TTX) minimally affected ADP recorded from the calyx of Held axon terminals, the slow capacitive discharge of axonal membrane has been implicated in the generation of axonal ADP (Borst et al., 1995), as suggested in a previous study on lizard myelinated motor axons using intra-axonal recordings (Barrett and Barrett, 1982).

In this context, it should be noted that ADP has been demonstrated to exhibit clear dependence on the initial membrane potentials. On depolarization of the axonal membrane, the amplitude of ADP decreased and occasionally reversed in polarity (Begum et al., 2016; Sierksma and Borst, 2017). This indicated that ADP not only consists of passive component, but also incorporates some

Received June 29, 2018; accepted July 26, 2018; First published August 09, 2018.

The authors declare no competing financial interests.

Author contributions: H.K. designed the experiments. S.O. performed the experiments. H.K. performed the numerical simulation. S.O. and H.K. performed data analysis. H.K. wrote the manuscript. Both authors approved the final version of the manuscript.

This work was supported by JSPS KAKENHI grant number 16 K15177 and $18 \mathrm{~K} 06514$ to HK.

Correspondence should be addressed to Haruyuki Kamiya, MD, PhD, Department of Neurobiology, Hokkaido University Graduate School of Medicine, Sapporo, 060-8638, Japan. E-mail: kamiya@med.hokudai.ac.jp.

DOI:http://dx.doi.org/10.1523/ENEURO.0254-18.2018

Copyright (C) 2018 Ohura and Kamiya

This is an open-access article distributed under the terms of the Creative Commons Attribution 4.0 International license, which permits unrestricted use, distribution and reproduction in any medium provided that the original work is properly attributed. active component due to the activation of voltagedependent conductance.

On the other hand, ADP was found to be largely suppressed by the application of low-concentration TTX to the same calyx of Held axon terminals (Kim et al., 2010). In that report, the author raised the possibility that certain subtypes of voltage-dependent $\mathrm{Na}^{+}$channels mediate ADP. $\mathrm{Na}^{+}$channels are functionally classified into at least three distinct subtypes: the transient-type $\left(I_{\mathrm{NaT}}\right)$, persistent-type $\left(\mathrm{I}_{\mathrm{NaP}}\right)$, and resurgent-type $\left(\mathrm{I}_{\mathrm{NaR}}\right)$. Involvement of slowly activating resurgent $\mathrm{Na}^{+}$current $\left(\mathrm{I}_{\mathrm{NaR}}\right)$ in axonal ADP was suggested in the study by Kim et al. (2010) because dialysis of a small peptide fragment of the $\beta 4$ subunit of $\mathrm{Na}^{+}$channels, which is an essential molecular component for $I_{\mathrm{NaR}}$, selectively enhanced ADP. As the reason for the controversial conclusion of these studies (Borst et al., 1995; Kim et al., 2010) remains unclear, thorough investigation is needed to clarify the mechanisms underlying axonal ADP in the central nervous system.

The functional significance of axonal ADP must also be addressed. It was widely considered that ADP lowers the threshold of subsequent action potentials, thereby enhancing the fidelity of spiking during high-frequency neuronal activity (Barrett and Barrett, 1982). Moreover, the prolonged time course of ADP was suggested to improve fine-tuning of presynaptic functions, such as action potential-driven $\mathrm{Ca}^{2+}$ entry and subsequent transmitter release, by affecting the voltage-dependent conductance shaping axonal action potentials such as $\mathrm{Na}^{+}$and $\mathrm{K}^{+}$ channels. However, detailed analysis of the axon terminals of calyx of Held revealed that ADP minimally affects $\mathrm{Ca}^{2+}$ currents by balancing and cancelling out changes in the driving force and gating of voltage-dependent $\mathrm{Ca}^{2+}$ channels (Clarke et al., 2016).

In this study, we examined the mechanisms underlying axonal ADP at hippocampal mossy fibers, where it was reported that prominent ADP follows axonal action potentials (Geiger and Jonas, 2000). Whole-cell recording from large axon terminals of hippocampal mossy fibers in combination with numerical simulation based on a realistic model of hippocampal mossy fibers (Engel and Jonas, 2005) was adopted to examine the ionic and electrical mechanisms underlying axonal ADP. We also closely investigated the influence of axonal ADP on action potential waveforms and $\mathrm{Ca}^{2+}$ current in presynaptic terminals to evaluate its functions for the activity-dependent tuning of presynaptic $\mathrm{Ca}^{2+}$ entry and subsequent transmitter release. 


\section{Materials and Methods}

\section{Animals and slice preparations}

C57BL/6J mice of either sex were used in this study and were treated according to the guidelines for the care and use of laboratory animals of Hokkaido University. Transverse hippocampal slices of 300- $\mu \mathrm{m}$ thickness were prepared from p14-29 mice (number of animals $=46$ ) as described previously (Kamiya, 2012; Ohura and Kamiya, 2018). Animals were anesthetized with ether, and the brain was dissected in an ice-cold sucrose solution containing the following: $40 \mathrm{~mm} \mathrm{NaCl}, 25 \mathrm{~mm} \mathrm{NaHCO}_{3}, 10 \mathrm{~mm}$ glucose, $150 \mathrm{~mm}$ sucrose, $4 \mathrm{~mm} \mathrm{KCl}, 1.25 \mathrm{~mm} \mathrm{NaH}_{2} \mathrm{PO}_{4}$, $0.5 \mathrm{mM} \mathrm{CaCl}_{2}$, and $7 \mathrm{mM} \mathrm{MgCl}_{2}$. Transverse slices were cut using a VT1200S microslicer (Leica Biosystems). The slices were then exchanged in a NMDG-HEPES recovery solution containing the following: $93 \mathrm{~mm} \mathrm{NMDG}, 2.5 \mathrm{~mm}$ $\mathrm{KCl}, 1.2 \mathrm{~mm} \mathrm{NaH}_{2} \mathrm{PO}_{4}, 30 \mathrm{~mm} \mathrm{NaHCO}_{3}, 20$ mm HEPES, 25 $\mathrm{mm}$ glucose, $5 \mathrm{~mm}$ Na-ascorbate, $2 \mathrm{~mm}$ thiourea, $3 \mathrm{~mm}$ Na-pyruvate, $10 \mathrm{~mm} \mathrm{MgSO}_{4}$, and $0.5 \mathrm{~mm} \mathrm{CaCl}_{2}$ and incubated for no longer than $15 \mathrm{~min}$ at $30-32^{\circ} \mathrm{C}$ (Ting et al., 2014). Then the solution was exchanged with standard artificial cerebrospinal fluid (ACSF) containing the following: $127 \mathrm{~mm} \mathrm{NaCl}, 1.5 \mathrm{~mm} \mathrm{KCl}, 1.2 \mathrm{mM} \mathrm{KH}_{2} \mathrm{PO}_{4}, 26 \mathrm{~mm}$ $\mathrm{NaHCO}_{3}, 10 \mathrm{~mm}$ glucose, $2.4 \mathrm{~mm} \mathrm{CaCl}$, and $1.3 \mathrm{~mm}$ $\mathrm{MgSO}_{4}$, and the slices were kept in an interface-type chamber saturated with $95 \% \mathrm{O}_{2}$ and $5 \% \mathrm{CO}_{2}$. The slices were incubated in the ACSF at room temperature for at least $1 \mathrm{~h}$ before experiments.

\section{Electrophysiology}

Mossy fiber boutons (MFBs) were visually identified under a microscope with IR-DIC optics (BX-51 WI, Olympus), as reported previously (Ohura and Kamiya, 2018; see also Geiger and Jonas, 2000; Alle and Geiger, 2006). Slices were continuously perfused at $\sim 2 \mathrm{ml} / \mathrm{min}$ with ACSF. In addition, the slice surface of the recording site was locally perfused with the drug-containing solution at $\sim 0.2 \mathrm{ml} / \mathrm{min}$ though a flow pipe with a $250-\mu \mathrm{m}$ open-tip diameter connected to an electromagnetic valve system (Valve Bank, Automate Scientific). All recordings were made at room temperature $\left(25 \pm 1^{\circ} \mathrm{C}\right)$ with a patch clamp amplifier (MultiClamp700B, Molecular Devices). Patch pipettes (typically 8-14 M $\Omega$ electrode resistance) were made from borosilicate glass with a microelectrode puller (Sutter P-97, Sutter Instruments). $\mathrm{Ca}^{2+}$-free ACSF (an equal concentration of $\mathrm{Mg}^{2+}$ replaced $\mathrm{Ca}^{2+} ; 0 \mathrm{mM} \mathrm{CaCl}{ }_{2}$ and $3.7 \mathrm{mM} \mathrm{MgSO}_{4}$ ) was perfused in the bath and focally applied to minimize the synaptic input from the surrounding cells. In whole-cell current clamp recordings, the patch pipettes were filled with an intracellular solution containing the following: $140 \mathrm{~mm}$ K-gluconate, $10 \mathrm{~mm} \mathrm{KCl}$, $0.2 \mathrm{~mm}$ EGTA, 2 mM MgATP, and $10 \mathrm{~mm}$ HEPES, adjusted to $\mathrm{pH}$ 7.2. Electrical stimuli for $200 \mu$ s were given every 10 $s$ at the granule cell layer of the dentate gyrus, except for in experiments shown in Fig. $3 E-I$, in which stimuli were delivered every $30 \mathrm{~s}$. The liquid junction potential was estimated as $-15 \mathrm{mV}$ using PCLAMP10 software and compensated for the holding potential. The series resistance and electrode capacitance were compensated before measurement. The recordings were adopted only when the resting membrane potentials were between -60 and $-85 \mathrm{mV}$ immediately after the break-in. The membrane potential was set to $-80 \mathrm{mV}$ manually by applying a small holding current if necessary (Geiger and Jonas, 2000). Input resistance was continuously monitored by injecting a hyperpolarizing current pulse $(-10 \mathrm{pA}, 300 \mathrm{~ms})$ in each sweep. MFBs with input resistance larger than $800 \mathrm{M} \Omega$ and series resistance lower than $70 \mathrm{M} \Omega$ were used for later analyses. The data were excluded if the series resistance changed by $>20 \%$ of the initial value during the recording. In voltage-clamp experiments, pipettes were filled with an internal solution containing the following: $145 \mathrm{~mm} \mathrm{CsCl}, 2 \mathrm{~mm} \mathrm{MgCl} 2$, $2 \mathrm{~mm} \mathrm{Na} \mathrm{NaTP}_{2}$, 0.3 mM NaGTP, $5 \mathrm{~mm} \mathrm{Na}_{2}$-phosphocreatinine, $10 \mathrm{~mm}$ HEPES, and $10 \mathrm{~mm}$ EGTA, adjusted to $\mathrm{pH}$ 7.2. To record the $\mathrm{Ca}^{2+}$ current, ACSF containing $1 \mu \mathrm{M}$ tetrodotoxin (TTX), $20 \mathrm{~mm}$ tetraethylammonium chloride (TEA), and $5 \mathrm{~mm}$ 4-aminopyridine (4AP) was focally applied to the recording sites. To adjust the osmolarity of the solution, the concentration of $\mathrm{NaCl}$ in the ACSF was lowered by $20 \mathrm{~mm}$. Leakage and capacitive currents were subtracted online using $\mathrm{P} / 4$ procedures. Series resistance $(57.2 \pm 3.3 \mathrm{M} \Omega$, $n=7$ ) was compensated by $50 \%-70 \%$. In some recordings, unclamped tail currents with a very slow time course appeared in an all-or-none manner, possibly reflecting spiking of the neighboring axons or boutons. These recordings with a time constant longer than $400 \mu$ s were excluded from analysis. Signals were filtered at $10 \mathrm{kHz}$ with a 4-pole Bessel filter and were digitized at $20 \mathrm{kHz}$ with a Digidata 1322A interface and 16-bit resolution (Molecular Devices). All data were acquired and analyzed offline with pClamp 10.7 software (Molecular Devices) and Origin 8J or 2015 (OriginLab).

\section{Simulation}

The simulated membrane potential $\left(V_{m}\right)$ at the hippocampal mossy fibers was calculated according to the model suggested by Engel and Jonas (2005) based on the data recorded from mossy fiber boutons. The model basically assumed a Hodgkin-Huxley-type model (Hodgkin and Huxley, 1952) adapted to channels in mossy fiber terminals, and $\mathrm{K}^{+}$channel inactivation was implemented multiplicatively with parameters of recombinant $\mathrm{K}_{\mathrm{v}} 1.4$ channels (Wissmann et al., 2003). Simulations were performed using NEURON 7.5 for Windows (Hines and Carnevale, 1997). The passive electrical properties of the axon were assumed to be uniform, with a specific membrane capacitance $\mathrm{Cm}$ of $1 \mu \mathrm{F} \mathrm{cm}^{-2}$, a specific membrane resistance $\mathrm{Rm}$ of $10,000 \Omega \mathrm{cm}^{2}$, and an intracellular resistivity Ri of $110 \Omega \mathrm{cm}$. The structure of the mossy fiber was approximated by a soma (diameter, $10 \mu \mathrm{m}$ ), 10 axonal cylinders (diameter, $0.2 \mu \mathrm{m}$; length, $100 \mu \mathrm{m}$ ), and 10 en passant boutons (diameter, $4 \mu \mathrm{m}$ ). The number of segments was $1 \mu \mathrm{m}^{-1}$, and the time step was $5 \mu \mathrm{s}$ in all simulations. The resting potential was assumed to be -80 $\mathrm{mV}$. The reversal potential of the leak conductance was set to $-81 \mathrm{mV}$ to maintain stability. Voltage-gated $\mathrm{Na}^{+}$ channels, $\mathrm{K}^{+}$channels, and leakage channels were inserted into the soma, axon, and boutons, respectively. The $\mathrm{Na}^{+}$conductance density was set to $50 \mathrm{mS} \mathrm{cm}^{-2}$ for 
the axon and boutons and $10 \mathrm{mS} \mathrm{cm}^{-2}$ for the soma. The $\mathrm{K}^{+}$conductance density was set to $36 \mathrm{mS} \mathrm{cm}^{-2}$ throughout all parts of the neurons. Action potentials were evoked by injection of depolarizing current into the 9th bouton (1 $\mathrm{ms}, 0.15 \mathrm{nA})$ or the soma (2 ms, $0.2 \mathrm{nA})$ in the simulation shown in Figs. $4 G$ and $4 H$, respectively. We conducted stimulation on the last (10th) bouton in a "pearl chain structure" to avoid sealed end effects. The equilibrium potentials for $\mathrm{Na}^{+}$and $\mathrm{K}^{+}$ions were assumed to be +50 $\mathrm{mV}$ and $-85 \mathrm{mV}$, respectively.

\section{Statistics}

All data are expressed as the mean \pm SEM. Statistical analysis was performed by nonparametric two-sided tests (Wilcoxon signed-rank test for paired data and MannWhitney $U$ test for unpaired data), and a $p$-value of $<0.05$ was accepted for statistical significance. All statistical analyses were conducted using R software (version 3.4.1).

\section{Chemicals}

Veratridine was purchased from Sigma-Aldrich. Tetrodotoxin was purchased from Funakoshi. All other chemicals were purchased from Wako Pure Chemical.

\section{Results}

\section{Slow ADP following axonal action potentials at hippocampal mossy fibers}

To characterize the detailed properties of ADP following action potentials, whole-cell current clamp recordings were made from large MFBs in mouse hippocampal slices (Fig. 1A). Long depolarizing current pulses $(20-120 \mathrm{pA}$, $500 \mathrm{~ms}$ ) in the current clamp configuration constantly evoked single action potentials to increasing currents (Fig. $1 B$ ), as reported previously (Geiger and Jonas, 2000; Bischofberger et al., 2006). Input resistance and the time constant of MFBs were also measured from voltage responses to hyperpolarizing current injection of $-10 \mathrm{pA}$ for $300 \mathrm{~ms}$. Input resistance and the decay time constant were $1.06 \pm 0.06 \mathrm{G} \Omega$ and $36.4 \pm 3.3 \mathrm{~ms}$, respectively ( $n$ $=20$ ), and were consistent with those reported in previous studies (Bischofberger et al., 2006; Szabadics and Soltesz, 2009). Action potentials were also evoked by extracellular stimulation at the granule cell layer of the dentate gyrus (Fig. 1C, left). The amplitude and half-width of action potentials evoked by stimulation of granule cells were $114.5 \pm 2.4 \mathrm{mV}$ and $863 \pm 34 \mu \mathrm{s}$, respectively $(n=$ 20). Alternatively, injection of short current pulses (500$800 \mathrm{pA}$ for $1 \mathrm{~ms}$ ) to the recorded bouton also elicited action potentials (Fig. $1 C$, right). The amplitude and halfwidth of the action potentials evoked by current injection were $113.8 \pm 2.6 \mathrm{mV}$ and $918 \pm 26 \mu \mathrm{s}$, respectively $(n=$ $6)$, which were not significantly different from those evoked by stimulation at the granule cell layer $(p=0.700$ and $p=0.422$ for amplitude and half duration, respectively).

In each stimulation mode of input stimulation or current injection, a small and prolonged ADP followed the action potentials in MFBs (Geiger and Jonas, 2000; Kamiya et al., 2002), as shown in Fig. $1 C$ (arrowheads). The amplitude and decay time constant of ADP by stimulation of
A

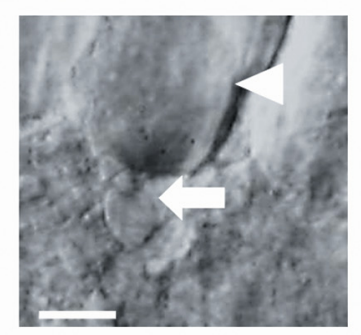

B

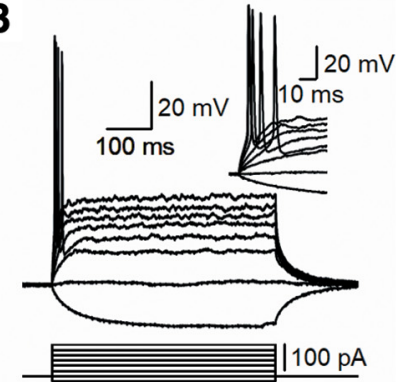

C
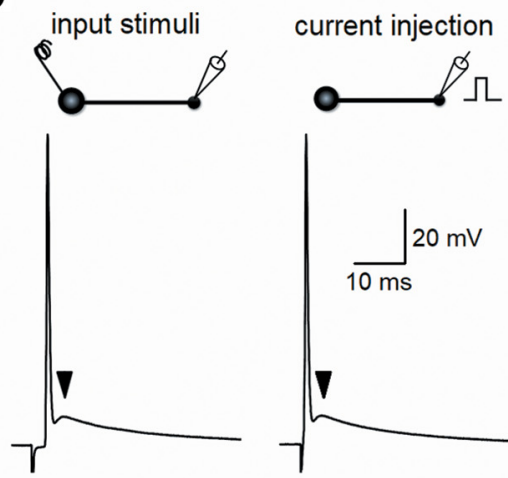

D

E
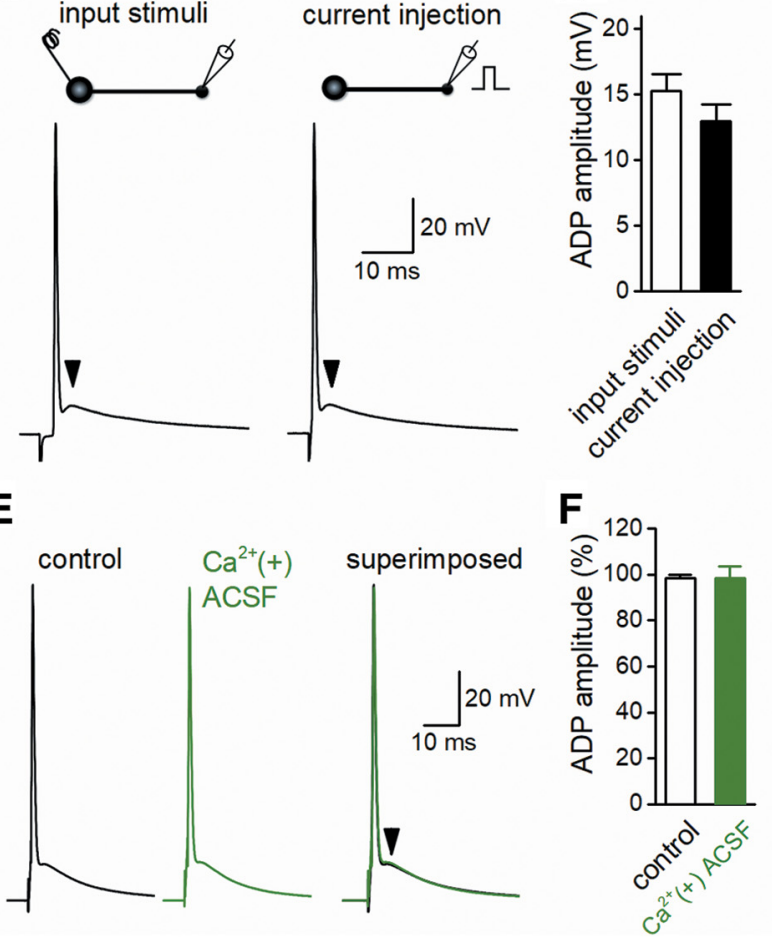

Figure 1. Prominent ADP following action potentials at MFBs in mouse hippocampal slices. A, IR-DIC image of the recorded bouton (arrow) and CA3 pyramidal cell (arrowhead). Scale bar represents $5 \mu \mathrm{m}$. $\boldsymbol{B}$, Whole-cell recordings confirmed typical membrane potential responses of MFBs with single action potentials in response to the current injection (-20- to 120-pA pulses for $500 \mathrm{~ms}, 20 \mathrm{pA}$ each step). $\boldsymbol{C}$, Action potential of MFBs evoked by input stimuli at the granule cell layer (left) and current injection at the recorded boutons (right). The arrowheads represent the peaks of ADP. $\boldsymbol{D}$, Summary data of the amplitude of ADP elicited by input stimuli (open column; $n=20$ ) or by current injection (closed column, $n=6$ ). $\boldsymbol{E}$, Effects of $\mathrm{Ca}^{2+}$-containing ACSF on action potentials elicited by current injection. $\boldsymbol{F}$, Summary of ADP amplitude in the absence (open column) and presence (closed column) of $\mathrm{Ca}^{2+}(n=8)$.

input fibers were $15.3 \pm 1.3 \mathrm{mV}$ and $41.6 \pm 3.8 \mathrm{~ms}$, respectively $(n=20)$, which were not significantly different from those evoked by current injection to the recorded boutons (13.0 $\pm 1.3 \mathrm{mV}$ and $43.6 \pm 5.5 \mathrm{~ms})$, as shown in Fig. $1 D(p=0.494$ for amplitude and $p=0.700$ for decay time constant). As these data were recorded in $\mathrm{Ca}^{2+}$-free ACSF to minimize the influence of synaptically released transmitters (Ohura and Kamiya, 2018), ADP was consid- 

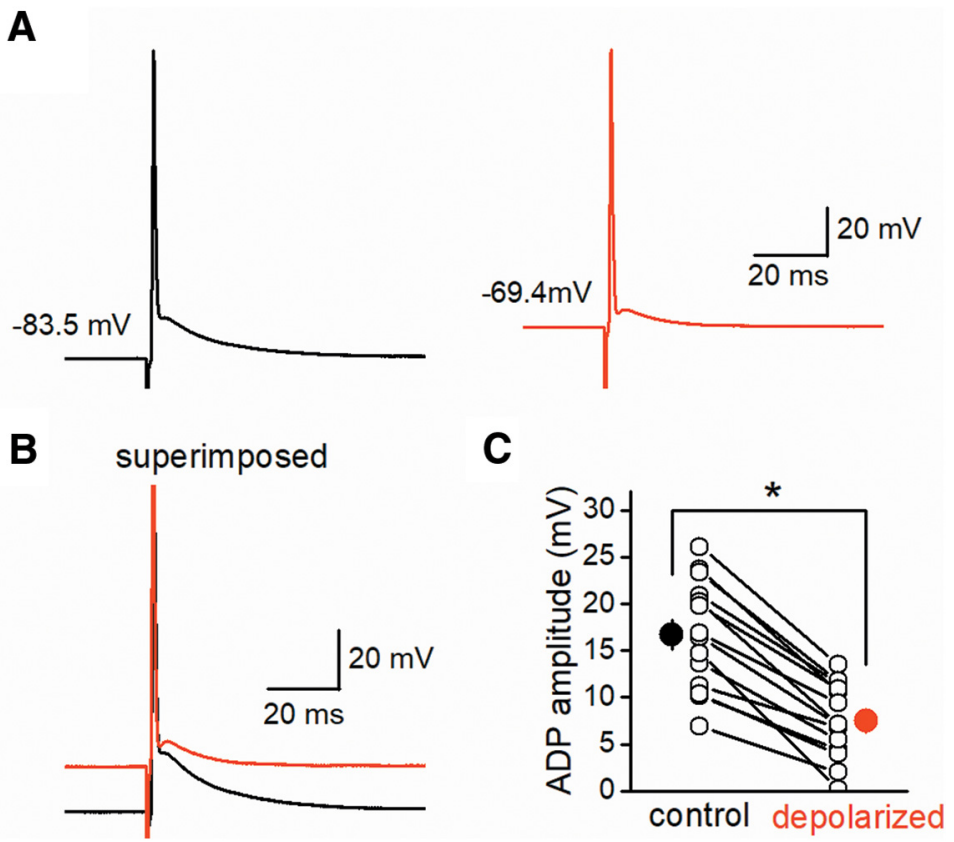

Figure 2. Dependence of ADP on initial membrane potentials. A, Action potentials were recorded at control (black) and depolarized (red) membrane potentials by injecting constant currents into the recorded boutons. Although the peak of action potentials was unaffected by changes in initial membrane potentials, the amplitude and the time course of ADP were significantly altered by changes in the membrane potentials. $\boldsymbol{B}$, Superimposed traces illustrate the voltage-dependence of ADP. $\boldsymbol{C}$, Summary data for ADP amplitude recorded at control and depolarized initial membrane potentials $(n=14, * p<0.05)$.

ered to have originated intrinsically from the membrane properties of MFBs.

Previous reports suggested that R-type $\mathrm{Ca}^{2+}$ channels contribute to ADP in CA1 pyramidal neurons (Metz et al., 2005), and mossy fiber terminals contain R-type $\mathrm{Ca}^{2+}$ channels (Gasparini et al., 2001; Li et al., 2007). However, any possible contribution of $\mathrm{R}$-type $\mathrm{Ca}^{2+}$ channels to $\mathrm{ADP}$ generation was omitted in the recording in $\mathrm{Ca}^{2+}$-free solution. To test for possible contribution of R-type $\mathrm{Ca}^{2+}$ channels in axonal ADP in the mossy fibers, we examined the effects of $\mathrm{Ca}^{2+}$-containing ACSF and found no significant changes in action potentials or ADP generated by short current injection $(p=0.742$ and $p=0.742$, respectively, $n=8$, Fig. $1 E, F$ ). This suggests that ADP at mossy fiber terminals was not mediated by $\mathrm{Ca}^{2+}$ channel-dependent components.

\section{Voltage dependence of axonal ADP}

To investigate the mechanisms underlying ADP, we first examined the voltage-dependence of ADP amplitude. For this purpose, membrane potentials were changed by injecting continuous currents into the recording MFBs. At positive membrane potentials relative to resting membrane potentials, the amplitude of ADP was decreased and the waveform was markedly altered (Fig. $2 A, B$ ). In these experiments, we measured membrane potentials at $5 \mathrm{~ms}$ after the peak of the action potentials because the peak of ADP was evident at that time point. The ADP amplitude was $16.7 \pm 1.6 \mathrm{mV}$ in the control conditions at $-79.1 \pm 0.6 \mathrm{mV}$, and decreased to $7.5 \pm 1.1 \mathrm{mV}$ at the depolarized conditions of $-66.2 \pm 0.9 \mathrm{mV}(n=14, p=$ 0.00012 , Fig. 2C). The negative correlation of ADP with initial membrane potentials was also reported at presynaptic terminals of the calyx of Held (Sierksma and Borst, 2017) or cerebellar basket cells (Begum et al., 2016).

\section{Sodium channel-dependent component of axonal ADP}

It was reported that the slow reactivation of resurgenttype $\mathrm{Na}^{+}$currents mediates ADP at the presynaptic terminals of the calyx of Held (Kim et al., 2010). Focal application of $0.5 \mu \mathrm{M}$ TTX to the recording site completely abolished both action potentials (from $108.9 \pm 4.0$ to 1.0 $\pm 0.4 \mathrm{mV}, n=6, p=0.0313$ ) and ADP (from $12.4 \pm 1.2$ to $0.4 \pm 0.2 \mathrm{mV}, n=6, p=0.0313$ ), as shown in Fig. $3 A$. To test for possible contribution of $\mathrm{Na}^{+}$channels to ADP, we examined the effects of TTX on ADP. For this purpose, brief current pulses of 2000-4300 pA for $1 \mathrm{~ms}$ were injected to mimic the short depolarization of action potentials $(103.7 \pm 6.7 \mathrm{mV}, n=6)$ in the presence of TTX (Fig. 3A). The peak amplitude of ADP was decreased to $10.3 \pm 1.3 \mathrm{mV}$ by TTX $(n=6)$, and the difference in ADP amplitudes between with and without TTX was significant $(p=0.0313)$, as shown in Fig. $3 D$. This suggests that TTX-sensitive $\mathrm{Na}^{+}$-channels partly mediate ADP at MFBs.

On the other hand, a previous study revealed that veratridine, an inhibitor of sodium channel inactivation, markedly enhanced and prolonged ADP at the calyx of Held presynaptic terminals (Kim et al., 2010). Therefore, we examined the effects of veratridine on action potentials and ADP at hippocampal MFBs. Application of $1 \mu \mathrm{M}$ veratridine had minimal effects on the action potentials (Fig. 3E, F). The amplitude and half-width of action potentials were $107.6 \pm 6.0 \mathrm{mV}$ and $1.02 \pm 0.03 \mathrm{~ms}$, respec- 


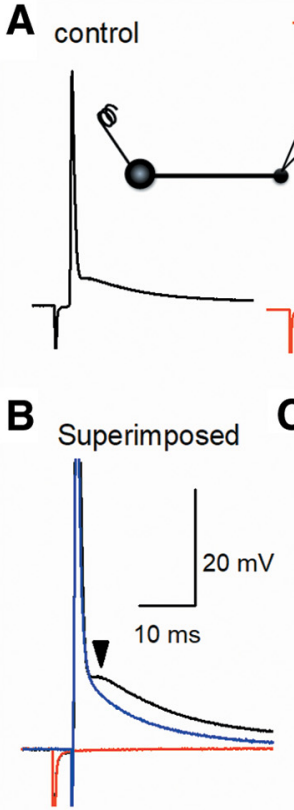

TTX

TTX \& current injection

E control \& veratridine
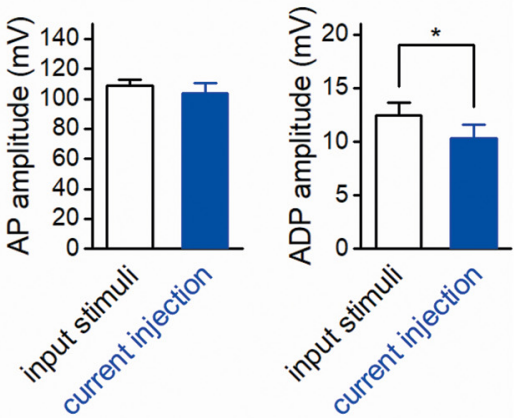

F control \& veratridine
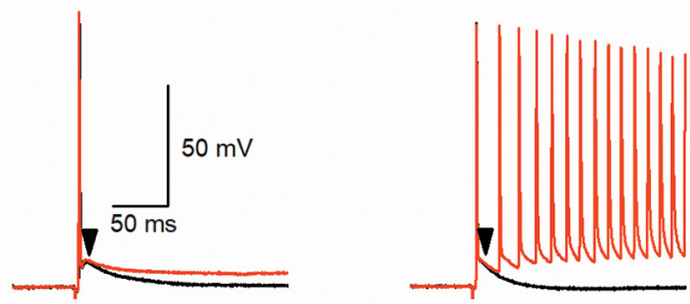

G

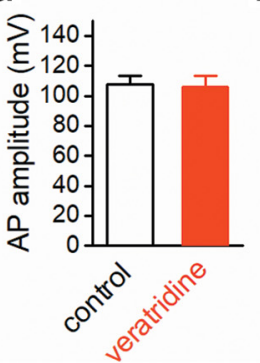

H

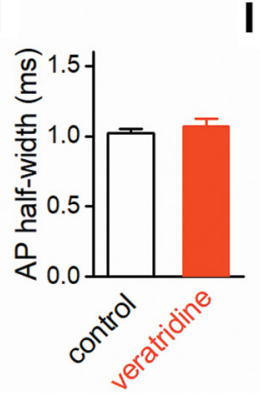

I

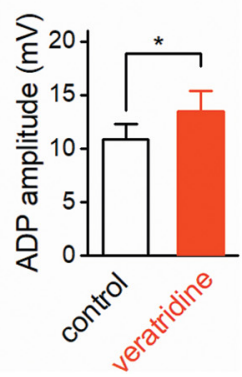

Figure 3. Involvement of $\mathrm{Na}^{+}$channels in axonal ADP. $\boldsymbol{A}$, Action potentials evoked by input stimuli (black) were completely suppressed by application of $0.5 \mu \mathrm{M}$ TTX (red). Large current injection into the recorded MFB elicited mock action potentials with similar time courses of action potentials and ADP (blue). $\boldsymbol{B}$, Superimposed control (black) and mock action potentials (blue) demonstrated that TTX-sensitive components overtook the TTXresistant slow ADP, suggesting that TTX-sensitive $\mathrm{Na}^{+}$-channels partly enhance ADP. C, $\boldsymbol{D}$, Comparison of control and mock action potentials $(\mathbf{C})$ and ADP $(\boldsymbol{D})$ amplitude $(n=6, *, p<0.05)$. $\boldsymbol{E}, \boldsymbol{F}$, Effects of focal application of $1 \mu \mathrm{M}$ veratridine, an inhibitor of $\mathrm{Na}^{+}$channel inactivation, on ADP. Veratridine enhanced and prolonged ADP $(\boldsymbol{E})$. In some cases, multiple action potentials $(\boldsymbol{F})$ were overlaid, as shown in the right panel. G-I, Summary data for the effects of veratridine on the amplitude $(\boldsymbol{G})$, half-width $(\boldsymbol{H})$ of action potentials, and the amplitude of $\operatorname{ADP}(\boldsymbol{I} ; n=6, *, p<$ 0.05). tively, in the control conditions, whereas they were 106.0 $\pm 7.4 \mathrm{mV}$ and $1.07 \pm 0.06 \mathrm{~ms}$, respectively, after application of veratridine $(n=6)$. The differences were not significant $(p=0.563$ and 0.688 , Fig. $3 G, H)$. However, the amplitude of ADP was significantly increased from $10.8 \pm$ 1.5 to $13.5 \pm 1.9 \mathrm{mV}$ by veratridine $(n=6, p=0.0313$, Fig. 3/). During application of veratridine for $10 \mathrm{~min}, 3$ of 6 recordings exhibited mild enhancement and prolongation of ADP, as shown in Fig. 3E, but the other 3 recordings accompanied multiple spikes overlaying enhanced ADP (Fig. 3F). These results suggest that veratridine-sensitive $\mathrm{Na}^{+}$channels contributed to the generation of ADP, although the amount varied among boutons. As ADP largely remained with TTX (Fig. 3B, D), a mechanism other than $\mathrm{Na}^{+}$channels is involved in the generation of ADP.

\section{Capacitive component of axonal ADP}

Next, we addressed the contribution of the component derived from slow capacitive discharge of the axonal membrane (Barrett and Barrett, 1982; Borst et al., 1995; David et al., 1995). As shown in Fig. 3A, brief current injection into the MFBs elicited prolonged depolarization resistant to the application of TTX. To measure the components of capacitive discharge, we evaluated the effects of 4-AP, which almost completely blocks potassium channels at MFBs (Alle et al., 2011), on TTX-resistant depolarization. Application of $2 \mathrm{~mm} 4-\mathrm{AP}$ increased the amplitude of the slow depolarization component at $5 \mathrm{~ms}$ from $11.6 \pm 0.9$ to $26.0 \pm 4.0 \mathrm{mV}(n=8, p=0.00781)$, as shown in Fig. $4 A, B$. The decay time constant was also increased by 4-AP (from $30.9 \pm 4.8$ to $37.6 \pm 6.1 \mathrm{~ms}, n=$ $8, p=0.00781$, Fig. 4C). These results suggest that delayed activation of voltage-dependent $\mathrm{K}^{+}$channels curtails the repolarizing phase of the brief depolarization by TTX, and the voltage responses elicited in the presence of TTX and 4-AP most likely represent capacitive components due to axonal membrane discharge. This notion is supported by the findings that the time constant (37.6 \pm $6.1 \mathrm{~ms}$ ) was not significantly different from that observed in hyperpolarization elicited by stepwise negative current injection $(37.7 \pm 6.7 \mathrm{~ms}, n=8 ; p=0.547$, Fig. $4 F)$. As expected from the passive nature of capacitive discharge, the time course of this component was voltageindependent (Fig. 4E). The amplitudes were $26.0 \pm 4.0 \mathrm{mV}$ at $-80 \mathrm{mV}$ and $25.3 \pm 3.9 \mathrm{mV}$ at $-70 \mathrm{mV}$, and the difference was not significant $(p=0.945)$. The decay time constant recorded at $-80 \mathrm{mv}(37.6 \pm 6.1 \mathrm{~ms})$ was not different from that at $-70 \mathrm{mV}(35.8 \pm 6.1 \mathrm{~ms}, n=8, p=$ 0.813 ).

To quantitatively evaluate the contribution of the capacitive component, we also conducted numerical simulation using the model described previously (Engel and Jonas, 2005). This was a realistic mossy fiber model incorporating the compartmental cable model mimicking the morphology of mossy fiber axons, as well as a HodgkinHuxley-type gating model of voltage-dependent $\mathrm{Na}^{+}$ channels that was obtained experimentally and implemented with inactivation of voltage-dependent $\mathrm{K}^{+}$channels. Hyperpolarization evoked by negative current injection was optimally fitted with the sum of two expo- 

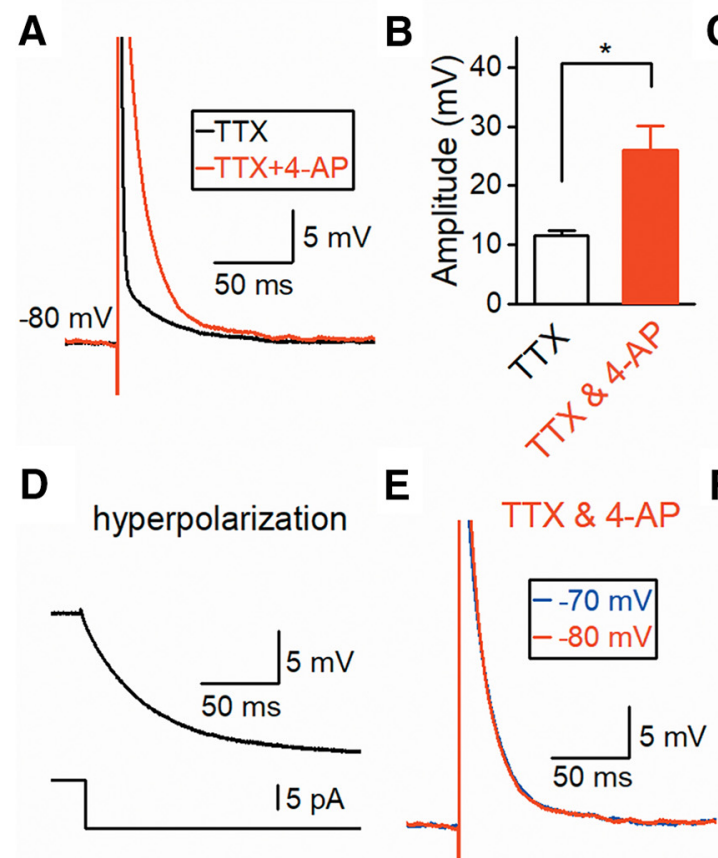

E
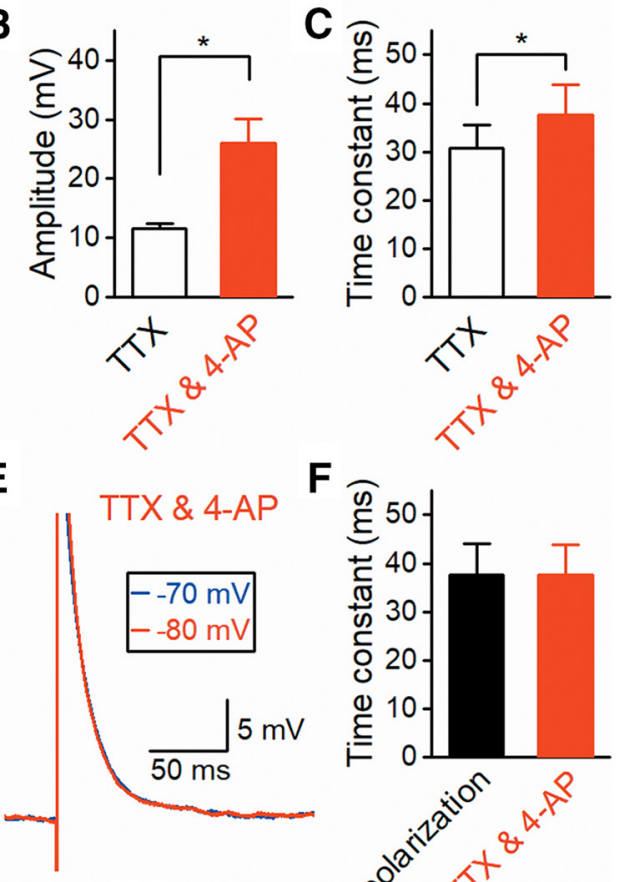

$\mathbf{F}$
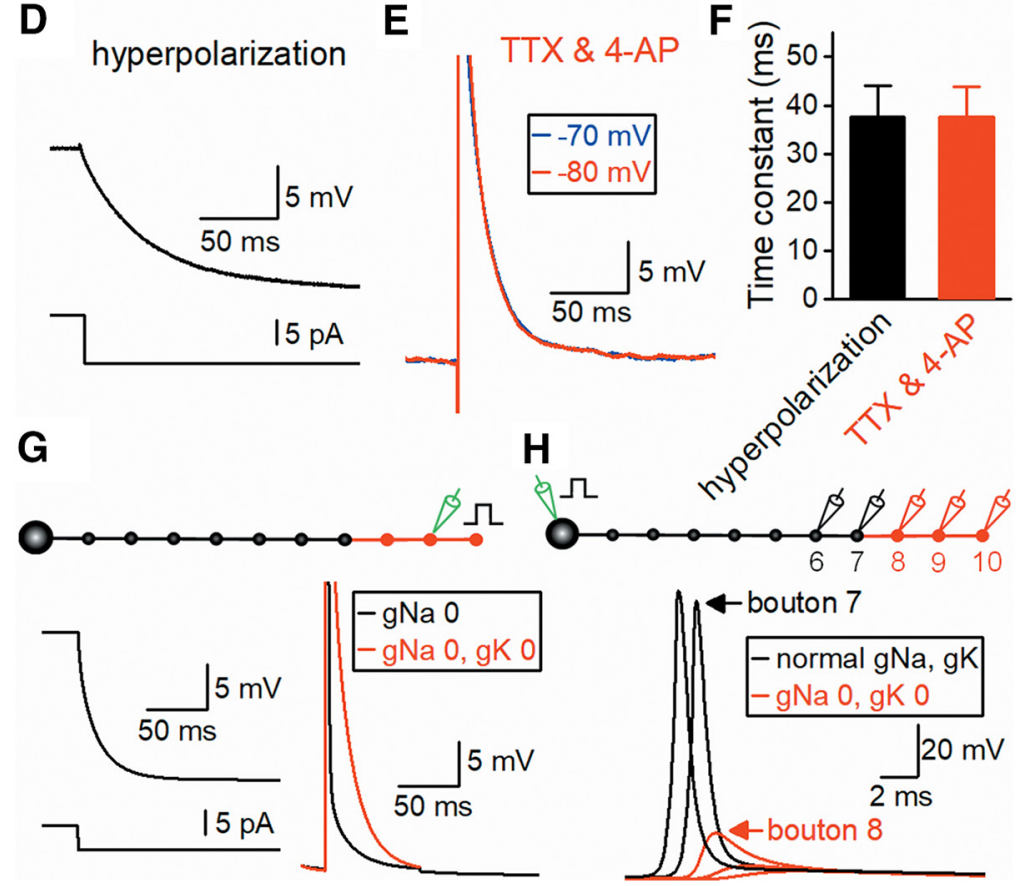

Figure 4. Contribution of capacitive slow discharge in the axonal ADP. A, Mock action potentials (black) elicited by large current injection into MFBs in the presence of TTX were prolonged by the addition of $2 \mathrm{~mm} 4-\mathrm{AP}$ (red), leaving the capacitive components of the axonal membrane. $\boldsymbol{B}, \boldsymbol{C}$, Summary data for the amplitude $(\boldsymbol{B})$ and decay time constant $(\boldsymbol{C})$ of $\operatorname{ADP}(n=8, *, p<0.05)$. $\boldsymbol{D}$, Time constant of MFBs measured by hyperpolarizing current injection (-10 pA, $300 \mathrm{~ms})$. E, Comparison of decay time course of capacitive components at different initial membrane potentials of -80 and $-70 \mathrm{mV}$. F, Summary data for decay time constants of hyperpolarization $(\boldsymbol{D})$ and the capacitive component of ADP at $-80 \mathrm{mV}(\boldsymbol{E})$. G. Simulated membrane potentials in the mossy fiber model by Engel and Jonas (2005) in response to hyperpolarizing current injection into distal MFBs (left). Brief large current injection elicited a similar response to those observed in $\boldsymbol{A}$ (right) when gNa and gK were omitted from the distal axons shown in red. See Methods for details. $\boldsymbol{H}$, Simulation of passive propagation of upstream action potentials to distal axons where gNa and gK were omitted.

nentials, reflecting two electrical components of boutons and the connecting axons, and the time constant of the dominant component was $17.0 \mathrm{~ms}$ (Fig. 4G, left). The decay time constant for short current injection, in which both $\mathrm{Na}^{+}$and $\mathrm{K}^{+}$conductance was reduced to 0 , was $15.0 \mathrm{~ms}$ (Fig. 4G, right).

We also conducted simulation for passive propagation of the action potentials through a thin axonal cable from the nearby MFBs. For this purpose, we reconstituted the propagation of action potentials elicited by injecting stimuli at the soma and calculated the voltage transients at the distal axons and the MFBs (Fig. 4H). Simulation demonstrated that the action potential of nearby MFBs (108.2 $\mathrm{mV}$ in amplitude) was passively propagated to the next MFBs (17.3 $\mathrm{mV}$ in amplitude). The spatial distribution constant of the passive propagation of transient signal, which we defined in this study as the distance that reduced the size of the transient signal to 1/e (37\%) without any active conductance, was estimated as 53.6 $\mu \mathrm{m}$, and this value was similar with that reported for Purkinje cell axons (Zorrilla de San Martin et al., 2017). Therefore, the capacitive component of ADP may reflect the propagation of action potentials at upstream axons and/or MFBs.

In the absence of active conductance, action potentials passively propagate and decay exponentially with distance. However, this spatial distribution of transient voltage changes is strongly filtered by the electrical cables of thin axons and should be different from and shorter than those of steady-state responses indicated by the length 
constant, which represents the duration for decay of the size of steady-state responses to 1/e.

These results suggest that the decay time course of ADP is mainly determined by the slow capacitive discharge of the axonal membrane following action potentials. Veratridinesensitive $\mathrm{Na}^{+}$channels and $4 \mathrm{AP}$-sensitive $\mathrm{K}^{+}$channels additionally contribute to ADP to modulate the time course in mouse hippocampal MFBs.

\section{Broadening of axonal action potentials by ADP}

Our previous study revealed short-term depression of axonal spikes, as recorded by loose-patch-clamp recording (Ohura and Kamiya, 2018). As application of veratridine selectively depressed the second spike with minimal effects on the first spike, we supposed that ADP following the first action potential affects the second action potential by steady-state inactivation of voltage-dependent $\mathrm{Na}^{+}$ channels. Thus, to examine the effects of ADP on activitydependent modulation of action potentials, we first examined whether steady-state depolarization affects the action potentials (Fig. 5A, B). The amplitude of the action potential was measured from the baseline before stimulation because it was difficult to detect the threshold of propagating action potentials because of their smooth rising phase. The small depolarization preceding AP (13.4 $\pm 0.8 \mathrm{mV}$ from control) caused no significant change in the peak amplitude (to $97.7 \pm 2.9 \%$ of control) or the half-width of action potentials (to $97.8 \pm 2.3 \%$ of control; $n=14, p=0.542$ and 0.326 ). The latency to the onset of action potentials was shortened to $85.9 \pm 5.7 \%$ of the control $(n=14, p=0.00842)$.

We then examined how ADP affects the subsequent action potentials. For this purpose, we recorded consecutive action potentials in response to the paired-pulse stimuli at short intervals (Fig. $5 \mathrm{C}$ ). The peak membrane potential was slightly reduced to $96.8 \pm 1.1 \%$ of the control at a 10-ms interval $(n=8, p=0.0173$, Fig. $5 D)$ but was not significantly changed at longer intervals (to 99.7 $\pm 0.5 \%, 100.0 \pm 0.2 \%$, and $99.8 \pm 0.2 \%$ of the control at $20-, 50-$, or 100 -ms intervals, respectively; $p=1,0.889$, and 0.674 for $20-, 50-$, and $100-\mathrm{ms}, n=8$, Fig. 5D). The peak reduction at the $10-\mathrm{ms}$ interval was possibly due to incomplete recovery from the inactivation of $\mathrm{Na}^{+}$channels (Engel and Jonas, 2005). We also examined the absolute value of the amplitude of action potentials. The amplitude of the second action potential was significantly reduced at 10-, 20-, and 50-ms intervals (to $86.8 \pm 2.3 \%$, $91.0 \pm 1.4 \%$, and $97.2 \pm 0.6 \%$ of the control, $p=$ $0.00195,0.000479$, and 0.00352 , respectively), and it almost recovered to the basal level at a $100-\mathrm{ms}$ interval (to $99.5 \pm 0.5 \%, p=0.287979$ ), as shown in Fig. $5 D$. These time courses of depression of the second action potentials were similar to those of ADP, which lasted for several tens of milliseconds.

We recently reported that axonal spikes recorded by loose-patch-clamp recording were markedly depressed in response to paired-pulse stimuli (Ohura and Kamiya, 2018). As the derivative of action potentials was found to be proportional to the extracellularly recorded axonal spikes by the loose-patch configuration (Meeks et al.,
2005; Ohura and Kamiya, 2018), we calculated the first derivative of the action potential by whole-cell recording (Fig. 5E). The second amplitude of the derivative of action potentials (Fig. 5F) was slightly lower than the first (88.4 \pm $4.1 \%, 92.6 \pm 1.5 \%, 96.4 \pm 0.9 \%$, and $97.8 \pm 0.5 \%$ of control for 10-, 20-, 50-, and 100-ms intervals, respectively). The differences were significant $(p=0.00781$, $0.00781,0.00781$, and 0.00781 , for $10-, 20-, 50-$, and 100 -ms intervals, $n=8$ ). The time course was consistent with that of axonal spikes recorded by loose-patch-clamp recording (Ohura and Kamiya, 2018).

We also examined the changes in duration of action potentials by paired stimuli. Repolarization was slightly slowed and the half-width of the action potentials was prolonged at short intervals $(113 \pm 5,110 \pm 2$, and $104 \pm$ $1 \%$ of the control at 10-, 20-, and 50-ms intervals, $p=$ $0.00781,0.00781$, and 0.00781 , respectively), but the difference was not significant at a 100-ms interval (102 \pm $1 \%$ of control, $p=0.148$ ), as shown in Fig. $5 G, H$. These findings were consistent with the previous study demonstrating activity-dependent broadening of action potentials by cumulated inactivation of potassium channels (Geiger and Jonas, 2000).

\section{Facilitation of presynaptic $\mathrm{Ca}^{2+}$ current by ADP}

Lastly, we examined whether ADP modifies the presynaptic $\mathrm{Ca}^{2+}$ current, which directly controls transmitter release and short-term plasticity. Pharmacologically isolated $\mathrm{Ca}^{2+}$ currents (Fig. 6A) exhibited a typical time course of slow activation followed by fast tail currents, as in the previous study (Bischofberger et al., 2002). The current-voltage (I-V) relationship was also similar to that reported previously. $\mathrm{Ca}^{2+}$ currents were activated from approximately $-40 \mathrm{mV}$ and reached a maximum amplitude of $134 \pm 15 \mathrm{pA}$ at $10 \mathrm{mV}(n=7)$, as shown in Fig. $6 B$. The voltage-dependence of the activation of $\mathrm{Ca}^{2+}$ current was also estimated by measuring tail currents and plotted against the voltage (Fig. $6 \mathrm{C}$ ). The steady-state activation data were fitted by a Boltzmann function with a slope factor of $10.4 \mathrm{mV}$ and midpoint potential of $-7.0 \mathrm{mV}$. These profiles of presynaptic $\mathrm{Ca}^{2+}$ currents in the MFBs were consistent with those reported in previous studies (Bischofberger et al., 2002; Li et al., 2007).

To explore the influence of ADP on the presynaptic $\mathrm{Ca}^{2+}$ influx, voltage-clamp recordings of $\mathrm{Ca}^{2+}$ currents were made using voltage commands mimicking the action potential waveforms recorded by paired-pulse stimuli shown in Fig. $5 \mathrm{C}$. The charge transfer of $\mathrm{Ca}^{2+}$ currents was measured as the integrated area under the curve. The half-width of $\mathrm{Ca}^{2+}$ currents was also measured as the duration between the time points of the half and peak heights. The $\mathrm{Ca}^{2+}$ currents elicited by the second action potential voltage-commands with ADP at $10 \mathrm{~ms}$ were slightly facilitated compared with those elicited by the first action potential commands at $115.2 \pm 8.5 \%$ of the control, and the half-width increased to $117.8 \pm 7.7 \%(n=7)$. These effects depended on the intervals of paired stimuli and were abolished at a 100-ms interval (to $103.0 \pm 2.7 \%$ for the charge and to $102.1 \pm 0.6 \%$ for the half-width). We considered this $\mathrm{Ca}^{2+}$ current facilitation by paired-pulse 
A

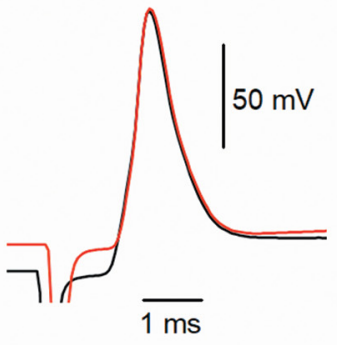

C

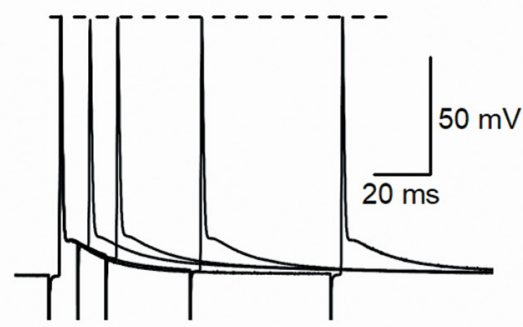

E

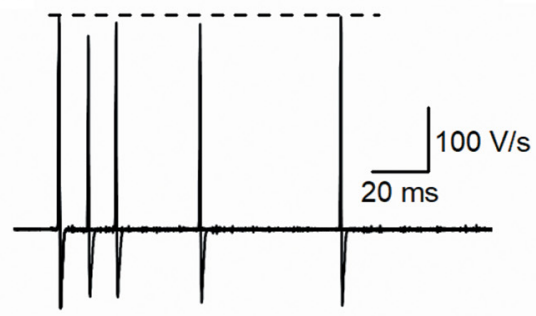

G

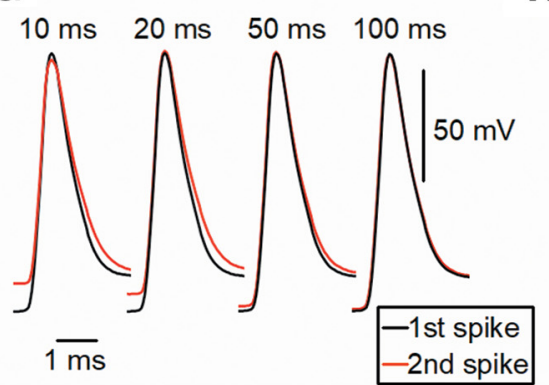

B

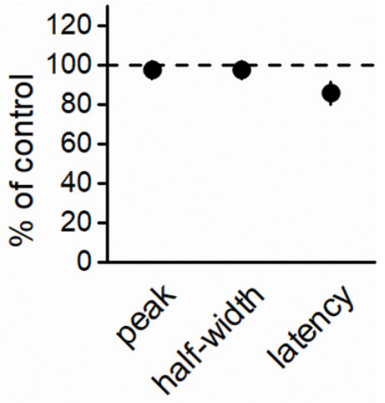

D

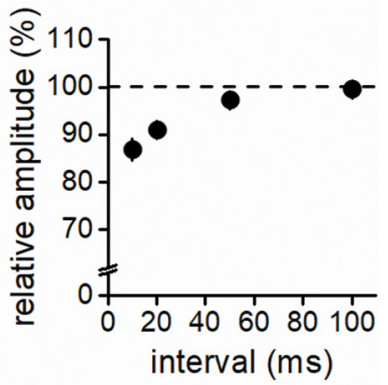

F

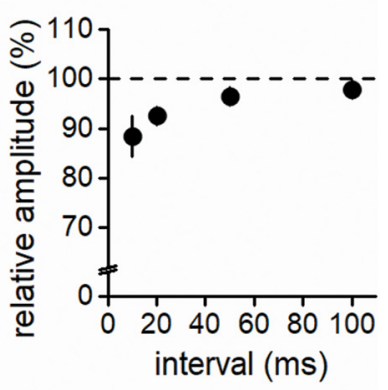

H

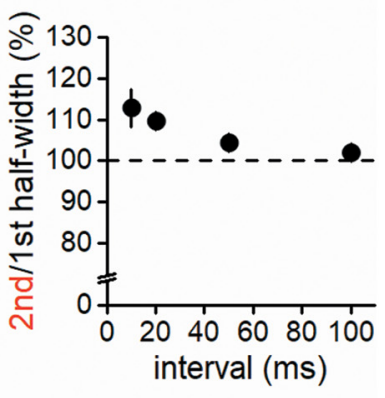

Figure 5. Broadening of axonal action potentials by the preceding ADP. $\boldsymbol{A}$, Effects of changes in initial membrane potentials on action potentials elicited by stimulation of input fibers recorded at depolarized (red) or resting (black) membrane potentials. $\boldsymbol{B}$, Summary data for the relative peak, half-width, and latency of action potentials $(n=14)$. $\boldsymbol{C}$, Superimposed traces of paired-pulse responses at $10-$, $20-, 50-$, and 100-ms intervals. $\boldsymbol{D}$, Summary data for the paired-pulse ratio of action potential amplitude measured from the onset of the second action potential $(n=8)$. $\boldsymbol{E}$, First derivatives calculated from paired-pulse responses are shown in $\boldsymbol{C}$ and $\boldsymbol{F}$, Summary data for the paired-pulse ratio of the first derivative waveform $(n=8)$. $\mathbf{G}$, Expanded traces of the first (black) and second (red) action potentials at different interspike intervals. $\boldsymbol{H}$, Summary data for the paired-pulse ratio of the action potential half-width $(n=8)$.

action potentials to be due to the broadening of action potentials, as shown in Fig. $5 \mathrm{G}$, or facilitation of $\mathrm{Ca}^{2+}$ channels by prolonged depolarization during ADP. To investigate these possibilities, "mock" action potentiallike voltage commands mimicking broadening of action potential but lacking ADP were applied to measure $\mathrm{Ca}^{2+}$ currents for comparison (Fig. 6D). In these recordings, $\mathrm{Ca}^{2+}$ currents were not facilitated (to $91.2 \pm 3.3 \%$ and $104.6 \pm 2.6 \%$ for 10 - and $100-m s$ intervals, respectively, $n=7$ ). At a $10-\mathrm{ms}$ interval, the difference in the facilitation of $\mathrm{Ca}^{2+}$ current between with and without ADP was significant $(p=0.0156)$. The half-width of the $\mathrm{Ca}^{2+}$ current was unaffected by mock action potentials with ADP (to $102.2 \pm 2.8 \%$ and $102.1 \pm 2.0 \%$ for 10 - and $100-\mathrm{ms}$ intervals, respectively, $n=7$ ). These results suggest that slight broadening of action potentials minimally affects $\mathrm{Ca}^{2+}$ entry, but ADP itself facilitates it, possibly by a mechanism similar to those recently reported at presyn- 

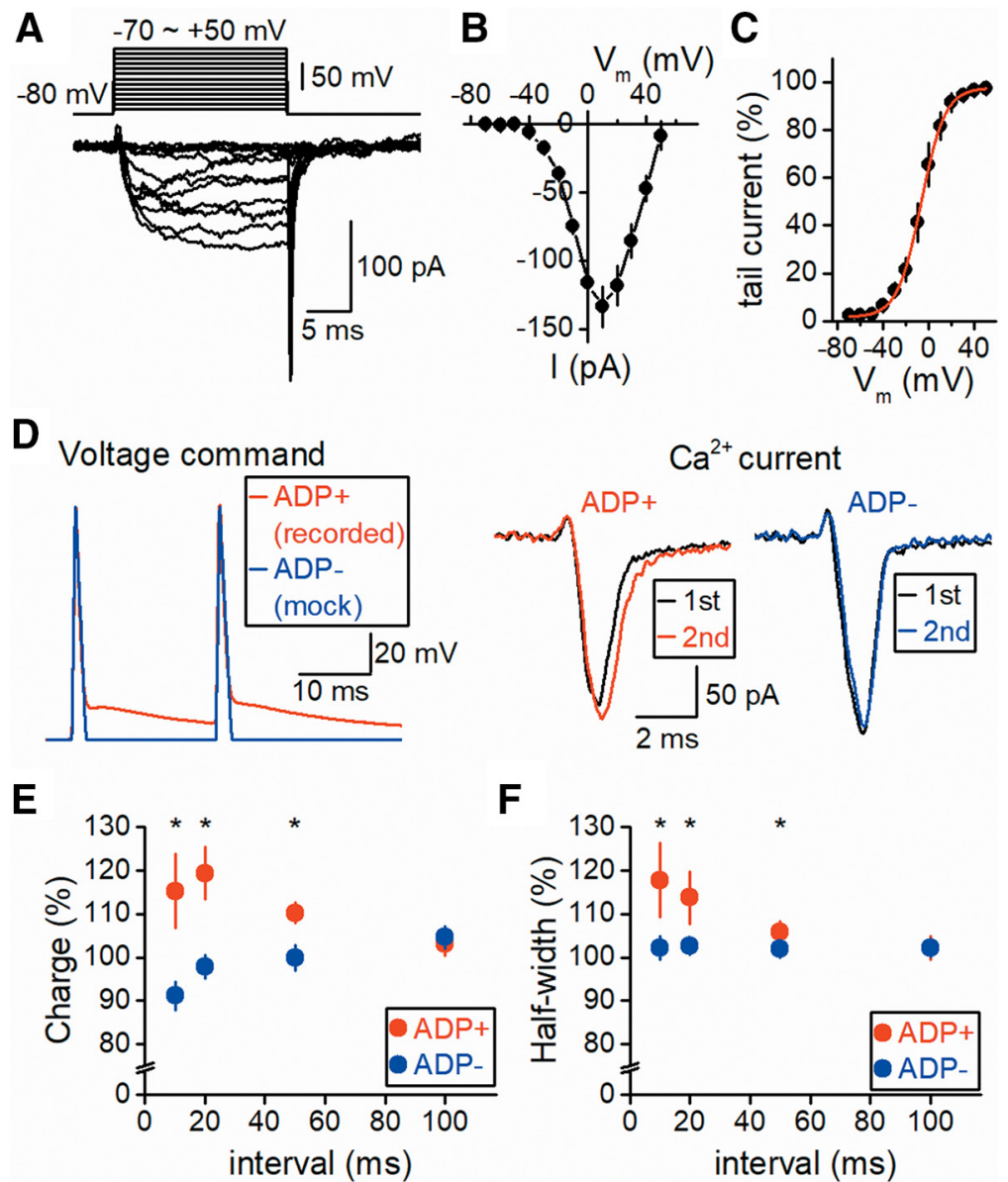

Figure 6. Facilitation of presynaptic $\mathrm{Ca}^{2+}$ influx by the axonal ADP. $\boldsymbol{A}, \mathrm{Ca}^{2+}$ currents in MFBs evoked by voltage steps from $-80 \mathrm{mV}$ to $-70 \sim 50 \mathrm{mV}$ for $20 \mathrm{~ms}$. $\boldsymbol{B}$, The averaged I-V relationships of presynaptic $\mathrm{Ca}^{2+}$ currents at MFBs. Current amplitudes were measured at the end of the voltage steps. $\boldsymbol{C}$, Voltage-dependence of activation of $\mathrm{Ca}^{2+}$ currents as shown by the amplitudes of tail currents. Data were normalized to the maximal value in each experiment and were fitted using a Boltzmann function $(n=7)$. $\boldsymbol{D}$, Voltage-clamp recording of $\mathrm{Ca}^{2+}$ currents using voltage commands mimicking the action potential waveforms elicited by paired-pulse stimuli (red). For comparison, mock action potential-like voltage commands mimicking broadening of action potentials by $10 \%$ in accordance with data in Fig. $5 \mathrm{H}$, but lacking ADP, were applied (blue). Superimposed $\mathrm{Ca}^{2+}$ currents evoked by the first and second voltage commands are shown in the right panels. $\boldsymbol{E}, \boldsymbol{F}$, Summary data for the paired-pulse ratio of charge transfer $(\boldsymbol{E})$ and half-width $(\boldsymbol{F})$ of $\mathrm{Ca}^{2+}$ currents $(n=7, *, p<0.05)$.

aptic terminals of cerebellar Purkinje cells (Zorrilla de San Martin et al., 2017). Although the underlying mechanisms remain to be elucidated, ADP following action potentials modulates $\mathrm{Ca}^{2+}$ entry into the presynaptic terminals by the second action potential, and may affect the short-term facilitation of transmitter release.

\section{Discussion}

In this study, we examined the mechanisms underlying the prominent ADP following axonal action potentials using direct whole-cell recordings from hippocampal mossy fiber terminals in mice. We found that the axonal ADP was generated predominantly by slow capacitive discharge of the axonal membrane, reflecting passive propagation of action potentials. Slow activating $\mathrm{Na}^{+}$channels also partly increase the capacitive component of the axonal ADP. On the other hand, voltage-dependent $\mathrm{K}^{+}$channels curtail the initial phase of ADP by accelerating repolarization. Furthermore, we also examined the functional consequences of axonal ADP in the regulation of presynaptic functions. We found that prolonged subthreshold depolarization of axonal ADP facilitates the presynaptic $\mathrm{Ca}^{2+}$ current, thereby possibly modulating short-term synaptic plasticity.

\section{Components of axonal ADP}

Action potentials recorded from the soma were often followed by ADP lasting for several tens of milliseconds, and were considered to regulate the fidelity of successive neuron firing during repetitive stimuli (Schwartzkroin, 1975; Storm, 1987). In addition, ADP is also known to be accompanied by action potentials propagating along axons. Thus far, axonal ADP was observed in several preparations allowing for direct recording from the axon and terminals such as in lizard motor axons (Barrett and Barrett, 1982), calyx of Held axon terminals (Borst et al., 1995), and hippocampal mossy fiber terminals (Geiger and Jonas, 2000). Therefore, the mechanisms of axonal ADP have been studied thoroughly, but remain somewhat 
controversial (Borst et al., 1995; Kim et al., 2010; Sierksma and Borst, 2017).

Regarding the mechanisms of axonal ADP, it has been widely accepted that the slow capacitive discharge of propagating action potentials contributes substantially to ADP (Barrett and Barrett, 1982), as expected from the cable properties of axons. As focal application of TTX minimally affected ADP at calyx of Held axon terminals (Borst et al., 1995), axonal ADP may be caused by, at least in part, a passive component due to capacitive discharge. In accordance with this notion, we found that the time course of slow repolarization of capacitive components, as measured in TTX and 4-AP conditions, was almost comparable to that of ADP.

On the other hand, ADP also demonstrated clear voltage-dependence, as shown in Fig. 2, which is different from the passive nature of the capacitive component. Therefore, involvement of voltage-dependent conductance in the generation of ADP is reasonable. In support of this notion, veratridine, which has complex effects on $\mathrm{Na}^{+}$ channels but exerts its facilitating action mainly by inhibiting inactivation (Ulbricht, 1998), robustly enhanced ADP, and it sometimes became overlaid with multiple spikes. In contrast, blocking $\mathrm{Na}^{+}$channels with $\mathrm{TTX}$ partly reduced ADP. These results were consistent with the contribution of some slowly activating voltage-dependent $\mathrm{Na}^{+}$channels to the generation of ADP, as reported in the calyx of Held axon terminals (Kim et al., 2010).

Previous studies demonstrated that slowly activating sodium channels, such as persistent-type $\mathrm{I}_{\mathrm{NaP}}$ (Yue et al., 2005; D’Ascenzo et al., 2009; Kole, 2011; Ghitani et al., 2016) or resurgent-type $I_{\mathrm{NaR}}$ (Raman and Bean, 1997), different from transient-type $I_{\mathrm{NaT}}$ responsible for generation of action potentials, are involved in ADP. We previously reported that ADP in the granule cell soma in the dentate gyrus, which was reported to highly express $\mathrm{I}_{\mathrm{NaR}}$ (Castelli et al., 2007), was markedly enhanced by veratridine (Ohura and Kamiya, 2018). This implies that ADP in hippocampal mossy fiber terminals may also be mediated by resurgent-type $I_{\mathrm{NaR}}$. Direct testing for the presence of $I_{\mathrm{NaR}}$ in future studies will help to reveal the contribution of specific $\mathrm{Na}^{+}$channels to ADP at hippocampal mossy fibers.

We also found that voltage-dependent $\mathrm{K}^{+}$channels sensitive to 4-AP are involved in the shaping of ADP. It was previously demonstrated that repolarization of action potentials at the MFBs is regulated by $\mathrm{K}_{\mathrm{v}} 1$ (Geiger and Jonas, 2000) and $K_{v} 3$ (Alle et al., 2011) voltage-dependent $\mathrm{K}^{+}$channels. $\mathrm{K}^{+}$currents elicited by action potential waveform commands are sensitive to 4-AP and were fully suppressed at $1 \mathrm{mM}$ (Alle et al., 2011). We confirmed that 4-AP at $2 \mathrm{~mm}$ substantially delayed the repolarization of mock action potentials elicited in the presence of $T T X$, and the time course of residual components was voltageindependent, as shown in Fig. 4E. These results suggest that voltage-dependent $\mathrm{K}^{+}$channels are also involved in the early phase of ADP to shorten the prolonged depolarization. This is consistent with the finding that ADP at the calyx of Held axon terminals is also negatively controlled by Kv1.1/1.2-type $\mathrm{K}^{+}$channels to prevent multiple spikes during ADP (Dodson et al., 2003). The contribution of $\mathrm{K}_{\mathrm{v}} 7$ should be examined in a future study, as it was found to alter the somatic ADP in pyramidal cells (Yue and Yaari, 2004; Gu et al., 2005; Brown and Randall, 2009) and is present on hippocampal mossy fibers (Martinello et al., 2015).

Taken together, we consider ADP at hippocampal mossy fibers to consist of passive and active components. Passive capacitive discharge dominates and determines the time course of ADP. As active components, possible slow activating voltage-dependent $\mathrm{Na}^{+}$channels sensitive to veratridine and TTX partly amplify the slow capacitive component. Voltage-dependent $\mathrm{K}^{+}$channels sensitive to 4-AP also participate in shaping the early phase of ADP at hippocampal mossy fibers.

This interpretation may clarify the voltage-dependence of axonal ADP (Fig. 2). In several previous studies, the voltage-dependence of axonal ADP on changes in membrane potentials was reported, and "apparent" reversal potentials also varied between different preparations (Begum et al., 2016; Sierksma and Borst, 2017). The differential contribution of capacitive mechanism, as well as $\mathrm{Na}^{+}$and $\mathrm{K}^{+}$channel-dependent mechanisms, may explain the complex voltage-dependence of axonal ADP. Our study clarified that sodium channel-dependent and -independent mechanisms underlie ADP at hippocampal mossy fibers.

\section{Role of ADP in activity-dependent modulation of axonal action potentials}

The functional consequence of ADP on subsequent axonal action potentials was examined thoroughly in previous studies. It was reported that ADP plays pivotal roles in ensuring reliable firing on multiple stimuli (Borst et al., 1995; Kim et al., 2010), as well as in modulating firing patterns (Bean, 2007; Sierksma and Borst, 2017). In this study, we examined activity-dependent modulation of the action potential waveform by ADP of preceding action potentials. ADP exhibited minimal effects on the peak of successive action potentials, except at very short intervals of $10 \mathrm{~ms}$, when $\mathrm{Na}^{+}$channels are not fully recovered from inactivation by the preceding action potentials (Brody and Yue, 2000; He et al., 2002; Engel and Jonas, 2005). However, peaks of the calculated first derivatives of action potentials, which are considered to reflect the maximal rate of the rising phase of action potentials, demonstrated paired-pulse depression for up to $100 \mathrm{~ms}$. This is consistent with our previous observation that axonal spikes recorded extracellularly using loose-patch clamp recording had paired-pulse depression following a similar time course (Ohura and Kamiya, 2018), because extracellularly recorded axonal spikes are theoretically proportional to the first derivative of action potentials (Meeks et al., 2005).

Furthermore, activity-dependent broadening of action potentials (Geiger and Jonas, 2000) was detectable even in paired-pulse protocols in this study. As suggested, accumulated inactivation of $\mathrm{K}_{\mathrm{v}} 1$-type voltage-dependent $\mathrm{K}^{+}$channels may cause activity-dependent broadening of action potentials at hippocampal mossy fibers. A similar 
mechanism may underlie ADP, although the magnitude of broadening is much smaller.

\section{Role of ADP in facilitation of the presynaptic $\mathrm{Ca}^{2+}$ current}

The shape of the presynaptic action potential determines the calcium influx to the presynaptic terminals, and thereby modulates transmitter release from the presynaptic terminals. Broadening of action potentials during repetitive stimuli was reported to enhance the calcium influx into presynaptic terminals (Geiger and Jonas, 2000; Bischofberger et al., 2002). Even in the paired-stimuli conditions, mild broadening of action potentials was observed, but it minimally affected the $\mathrm{Ca}^{2+}$ current elicited by mock action potentials without ADP, as shown in Fig. $6 D$. Although it is unclear why the $\mathrm{Ca}^{2+}$ current was not facilitated by paired-pulse, the positive effects of spike broadening may be counteracted or cancelled by residual inactivation of $\mathrm{Ca}^{2+}$ channels at short intervals. Slight changes in action potential rise times may also contribute to this apparent discrepancy.

On the other hand, $\mathrm{Ca}^{2+}$ currents elicited by voltageclamp commands of the recorded action potentials with ADP were slightly but significantly facilitated. Recently, direct recording from Purkinje cell axon terminals revealed that prior subthreshold depolarization facilitated $\mathrm{Ca}^{2+}$ currents (Zorrilla de San Martin et al., 2017). Although the detailed biophysical mechanism awaits future investigation, a similar mechanism may underlie the paired-pulse facilitation of $\mathrm{Ca}^{2+}$ currents observed in this study.

\section{Functional implications}

Axonal ADP following action potentials is a fundamental and important upstream process of transmitter release, which accordingly affects short-term synaptic plasticity. In this study, we found that the axonal ADP may facilitate presynaptic $\mathrm{Ca}^{2+}$ currents elicited by action potentials. As it has been demonstrated that somatic depolarization also affects transmitter release from MFBs in a $\mathrm{Ca}^{2+}$-independent manner (Scott et al., 2008), $\mathrm{Ca}^{2+}$ current facilitation as well as $\mathrm{Ca}^{2+}$-independent facilitation of transmitter release may be involved in the activity-dependent short-term plasticity at synapses. Simultaneous recording from both presynaptic MFBs and postsynaptic pyramidal cells (Vyleta and Jonas, 2014; Midorikawa and Sakaba, 2017) to quantitatively correlate presynaptic $\mathrm{Ca}^{2+}$-signaling with postsynaptic EPSPs will clarify the detailed functions of axonal ADP for the short-term plasticity at hippocampal mossy fiber synapses.

\section{References}

Alle H, Geiger JR (2006) Combined analog and action potential coding in hippocampal mossy fibers. Science 311:1290-1293. CrossRef Medline

Alle $\mathrm{H}$, Kubota $\mathrm{H}$, Geiger JR (2011) Sparse but highly efficient $\mathrm{K}_{\mathrm{v}} 3$ outpace $\mathrm{BK}_{\mathrm{Ca}}$ channels in action potential repolarization at hippocampal mossy fiber boutons. J Neurosci 31:8001-8012. CrossRef Medline

Barrett EF, Barrett JN (1982) Intracellular recording from vertebrate myelinated axons: mechanism of the depolarizing afterpotential. J Physiol 323:117-144. Medline
Bean BP (2007) The action potential in mammalian central neurons. Nat Rev Neurosci 8:451-465. CrossRef Medline

Begum R, Bakiri Y, Volynski KE, Kullmann DM (2016) Action potential broadening in a presynaptic channelopathy. Nat Commun 7:12102. CrossRef Medline

Bischofberger J, Geiger JR, Jonas P (2002) Timing and efficacy of $\mathrm{Ca}^{2+}$ channel activation in hippocampal mossy fiber boutons. J Neurosci 22:10593-10602. Medline

Bischofberger J, Engel D, Li L, Geiger JR, Jonas P (2006) Patchclamp recording from mossy fiber terminals in hippocampal slices. Nat Protoc 1:2075-2078.

Borst JG, Helmchen F, Sakmann B (1995) Pre- and postsynaptic whole-cell recordings in the medial nucleus of the trapezoid body of the rat. J Physiol 489:825-840. CrossRef

Brody DL, Yue DT (2000) Release-independent short-term synaptic depression in cultured hippocampal neurons. J Neurosci 20:24802494. Medline

Brown JT, Randall AD (2009) Activity-dependent depression of the spike after-depolarization generates long-lasting intrinsic plasticity in hippocampal CA3 pyramidal neurons. J Physiol 587:1265-1281. CrossRef Medline

Castelli L, Nigro MJ, Magistretti J (2007) Analysis of resurgent sodium-current expression in rat parahippocampal cortices and hippocampal formation. Brain Res 1163:44-55. CrossRef Medline

Clarke SG, Scarnati MS, Paradiso KG (2016) Neurotransmitter release can be stabilized by a mechanism that prevents voltage changes near the end of action potentials from affecting calcium currents. J Neurosci 36:11559-11572. CrossRef Medline

D'Ascenzo M, Podda MV, Fellin T, Azzena GB, Haydon P, Grassi C (2009) Activation of mGluR5 induces spike afterdepolarization and enhanced excitability in medium spiny neurons of the nucleus accumbens by modulating persistent $\mathrm{Na}^{+}$currents. J Physiol 587: 3233-3250. CrossRef

Debanne D, Campanac E, Bialowas A, Carlier E, Alcaraz G (2011) Axon physiology. Physiol Rev 91:555-602. CrossRef Medline

David G, Modney B, Scappaticci KA, Barrett JN, Barrett EF (1995) Electrical and morphological factors influencing the depolarizing after-potential in rat and lizard myelinated axons. J Physiol 489: 141-157. CrossRef

Dodson PD, Billups B, Rusznák Z, Szûcs G, Barker MC, Forsythe ID (2003) Presynaptic rat Kv1.2 channels suppress synaptic terminal hyperexcitability following action potential invasion. J Physiol 550: 27-33. CrossRef Medline

Engel D, Jonas P (2005) Presynaptic action potential amplification by voltage-gated $\mathrm{Na}^{+}$channels in hippocampal mossy fiber boutons. Neuron 45:405-417. CrossRef Medline

Gasparini S, Kasyanov AM, Pietrobon D, Voronin LL, Cherubini E (2001) Presynaptic R-type calcium channels contribute to fast excitatory synaptic transmission in the rat hippocampus. J Neurosci 21:8715-8721. Medline

Geiger JR, Jonas P (2000) Dynamic control of presynaptic $\mathrm{Ca}^{2+}$ inflow by fast-inactivating $\mathrm{K}^{+}$channels in hippocampal mossy fiber boutons. Neuron 28:927-939. Medline

Ghitani N, Bayguinov PO, Basso MA, Jackson MB (2016) A sodium afterdepolarization in rat superior colliculus neurons and its contribution to population activity. J Neurophysiol 116:191-200.

Gu N, Vervaeke K, Hu H, Storm JF (2005) Kv7/KCNQ/M and HCN/h, but not KCa2/SK channels, contribute to the somatic medium after-hyperpolarization and excitability control in CA1 hippocampal pyramidal cells. J Physiol 566:689-715. CrossRef

$\mathrm{He} \mathrm{Y,} \mathrm{Zorumski} \mathrm{CF,} \mathrm{Mennerick} \mathrm{S} \mathrm{(2002)} \mathrm{Contribution} \mathrm{of} \mathrm{presynaptic}$ $\mathrm{Na}^{+}$channel inactivation to paired-pulse synaptic depression in cultured hippocampal neurons. J Neurophysiol 87:925-936. CrossRef Medline

Hines ML, Carnevale NT (1997) The NEURON simulation environment. Neural Comput 9:1179-1209. Medline

Hodgkin AL, Huxley AF (1952) A quantitative description of membrane current and its application to conduction and excitation in nerve. J Physiol 116:497-506. 
Kamiya H, Ozawa S, Manabe T (2002) Kainate receptor-dependent short-term plasticity of presynaptic $\mathrm{Ca}^{2+}$ influx at the hippocampal mossy fiber synapses. J Neurosci 22:9237-9243. Medline

Kamiya H (2012) Photochemical inactivation analysis of temporal dynamics of postsynaptic native AMPA receptors in hippocampal slices. J Neurosci 32:6517-6524. CrossRef Medline

Kim JH, Kushmerick C, von Gersdorff H (2010) Presynaptic resurgent $\mathrm{Na}^{+}$currents sculpt the action potential waveform and increase firing reliability at a CNS nerve terminal. J Neurosci 30:1547915490. CrossRef

Kole MH (2011) First node of Ranvier facilitates high-frequency burst encoding. Neuron 71:671-682. CrossRef Medline

Kole MH, Stuart GJ (2012) Signal processing in the axon initial segment. Neuron 73:235-247. CrossRef Medline

Li L, Bischofberger J, Jonas P (2007) Differential gating and recruitment of $\mathrm{P} / \mathrm{Q}-, \mathrm{N}-$, and R-type $\mathrm{Ca}^{2+}$ channels in hippocampal mossy fiber boutons. J Neurosci 27:13420-13429. CrossRef Medline

Martinello K, Huang Z, Lujan R, Tran B, Watanabe M, Cooper EC, Brown DA, Shah MM (2015) Cholinergic afferent stimulation induces axonal function plasticity in adult hippocampal granule cells. Neuron 85:346-363. CrossRef Medline

Meeks JP, Jiang X, Mennerick S (2005) Action potential fidelity during normal and epileptiform activity in paired soma-axon recordings from rat hippocampus. J Physiol 566:425-441. CrossRef Medline

Metz AE, Jarsky T, Martina M, Spruston N (2005) R-type calcium channels contribute to afterdepolarization and bursting in hippocampal CA1 pyramidal neurons. J Neurosci 25:5763-5773. CrossRef Medline

Midorikawa M, Sakaba T (2017) Kinetics of releasable synaptic vesicles and their plastic changes at hippocampal mossy fiber synapses. Neuron 96:1033-1040. CrossRef Medline

Ohura S, Kamiya H (2018) Short-term depression of axonal spikes at the mouse hippocampal mossy fibers and sodium channeldependent modulation. eNeuro 5:pii: ENEURO.0415-17.2018.

Raman IM, Bean BP (1997) Resurgent sodium current and action potential formation in dissociated cerebellar Purkinje neurons. J Neurosci 17:4517-4526. Medline
Schwartzkroin PA (1975) Characteristics of CA1 neurons recorded intracellularly in the hippocampal in vitro slice preparation. Brain Res 85:423-436. Medline

Scott R, Ruiz A, Henneberger C, Kullmann DM, Rusakov DA (2008) Analog modulation of mossy fiber transmission is uncoupled from changes in presynaptic $\mathrm{Ca}^{2+}$. J Neurosci 28:7765-7773. CrossRef Medline

Sierksma MC, Borst JGG (2017) Resistance to action potential depression of a rat axon terminal in vivo. Proc Natl Acad Sci U S A 114:4249-4254. CrossRef Medline

Storm JF (1987) Action potential repolarization and a fast afterhyperpolarization in rat hippocampal pyramidal cells. J Physiol 385:733-759. CrossRef

Szabadics J, Soltesz I (2009) Functional specificity of mossy fiber innervation of GABAergic cells in the hippocampus. J Neurosci 29:4239-4251. CrossRef Medline

Ting JT, Daigle TL, Chen Q, Feng G (2014) Acute brain slice methods for adult and aging animals: application of targeted patch clamp analysis and optogenetics. Methods Mol Biol 1183:221-242. CrossRef Medline

Ulbricht W (1998) Effects of veratridine on sodium currents and fluxes. Rev Physiol Biochem Pharmacol 133:1-54. Medline

Vyleta NP, Jonas P (2014) Loose coupling between $\mathrm{Ca}^{2+}$ channels and release sensors at a plastic hippocampal synapse. Science 343:665-670. CrossRef Medline

Wissmann R, Bildl W, Oliver D, Beyermann M, Kalbitzer HR, Bentrop D, Fakler B (2003) Solution structure and function of the "tandem inactivation domain" of the neuronal A-type potassium channel Kv1.4. J Biol Chem 278:16142-16150. CrossRef Medline

Yue C, Yaari Y (2004) KCNQ/M channels control spike afterdepolarization and burst generation in hippocampal neurons. J Neurosci 24:4614-4624. CrossRef Medline

Yue C, Remy S, Su H, Beck H, Yaari Y (2005) Proximal persistent $\mathrm{Na}+$ channels drive spike afterdepolarizations and associated bursting in adult CA1 pyramidal cells. J Neurosci 25:9704-9720. CrossRef Medline

Zorrilla de San Martin J, Trigo FF, Kawaguchi SY (2017) Axonal $\mathrm{GABA}_{\mathrm{A}}$ receptors depolarize presynaptic terminals and facilitate transmitter release in cerebellar Purkinje cells. J Physiol 595:74777493. CrossRef Medline 